
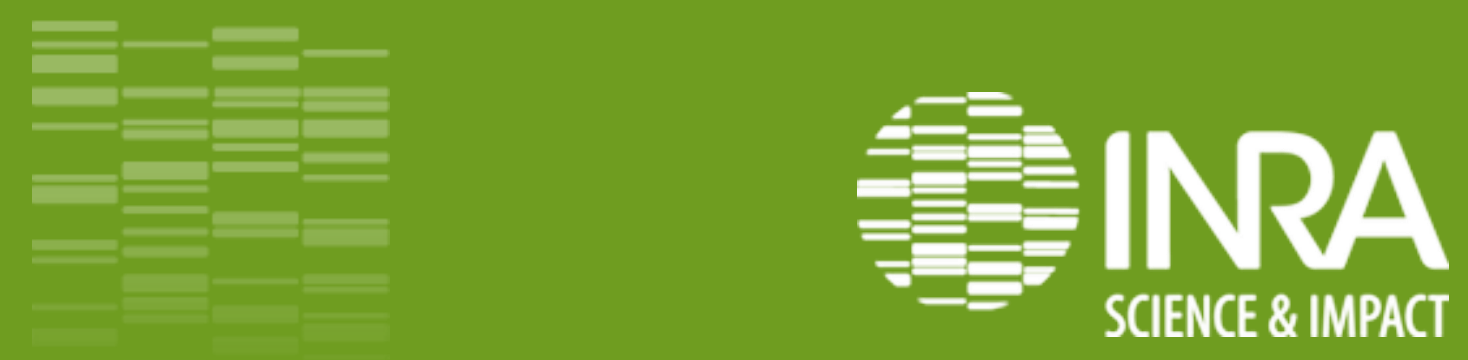

\title{
Comparison of lucerne genotypes and varieties in pure and mixed stands
}

B. Julier, G. Louarn, F. Gastal, F. Surault, J.P. Sampoux, A. Maamouri

URP3F, Lusignan, France

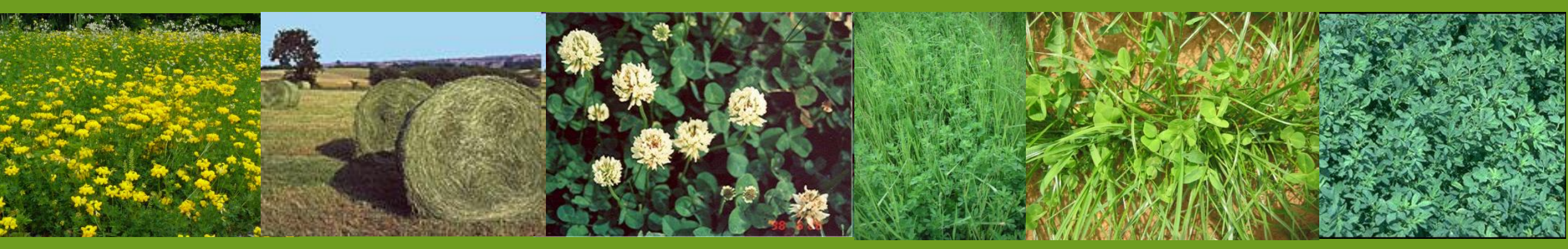

$\sin$

bernadette.julier@lusignan.inra.fr 


\section{Context}

- agronomic, economic and environmental advantages of mixtures

- Lucerne varieties are bred and evaluated in monoculture

- two questions:

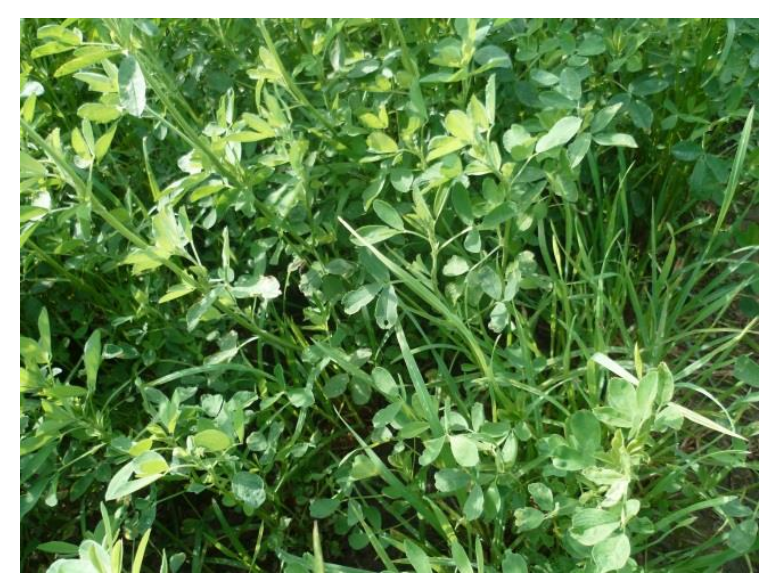

- is the ranking of varieties in monoculture the same as in mixture?

- in mixtures, does the ranking of the varieties of one species depend on the variety of the companion species? 


\section{Is the ranking of varieties in monoculture the same as in mixture?}

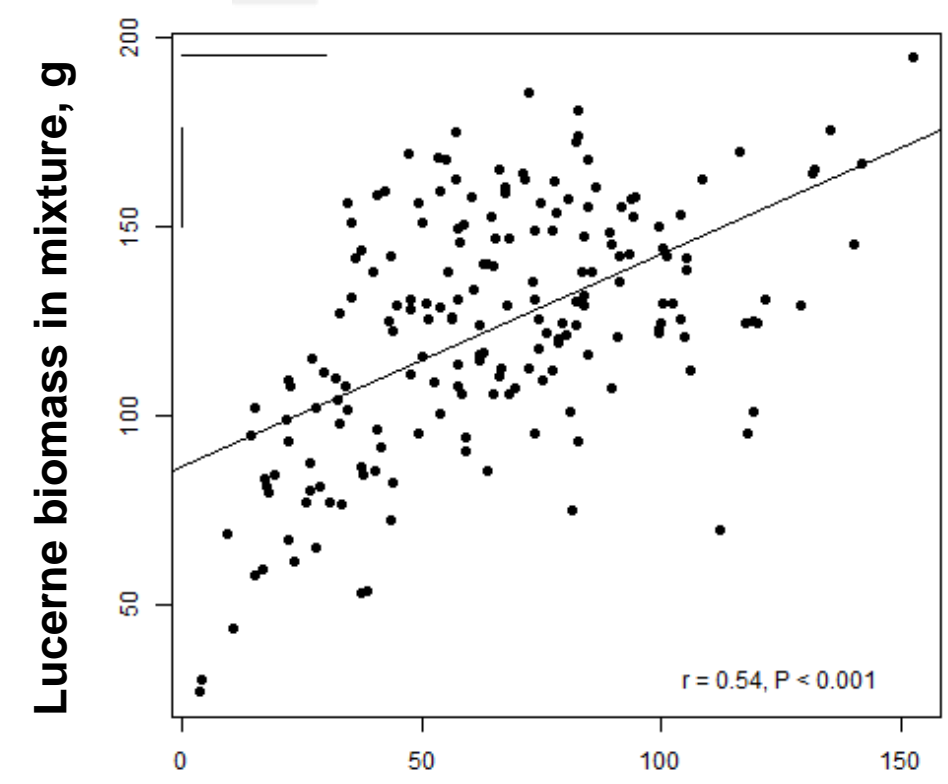

Lucerne biomass in monoculture, $\mathbf{g}$
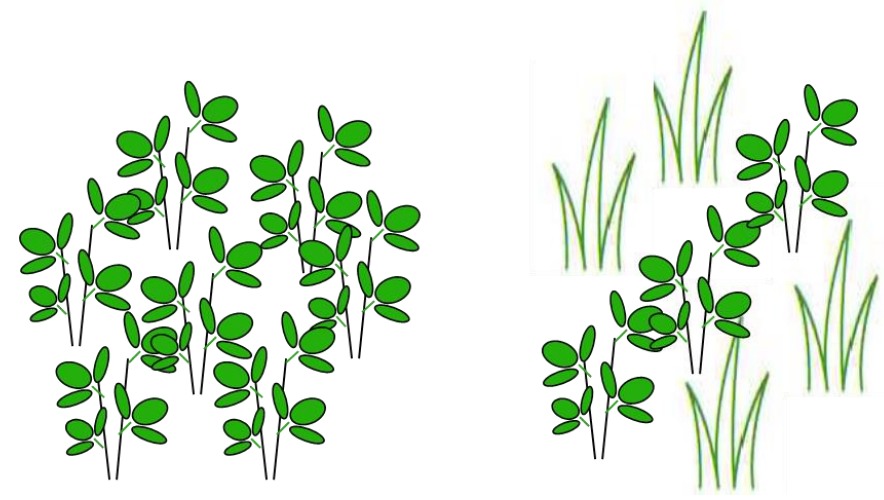
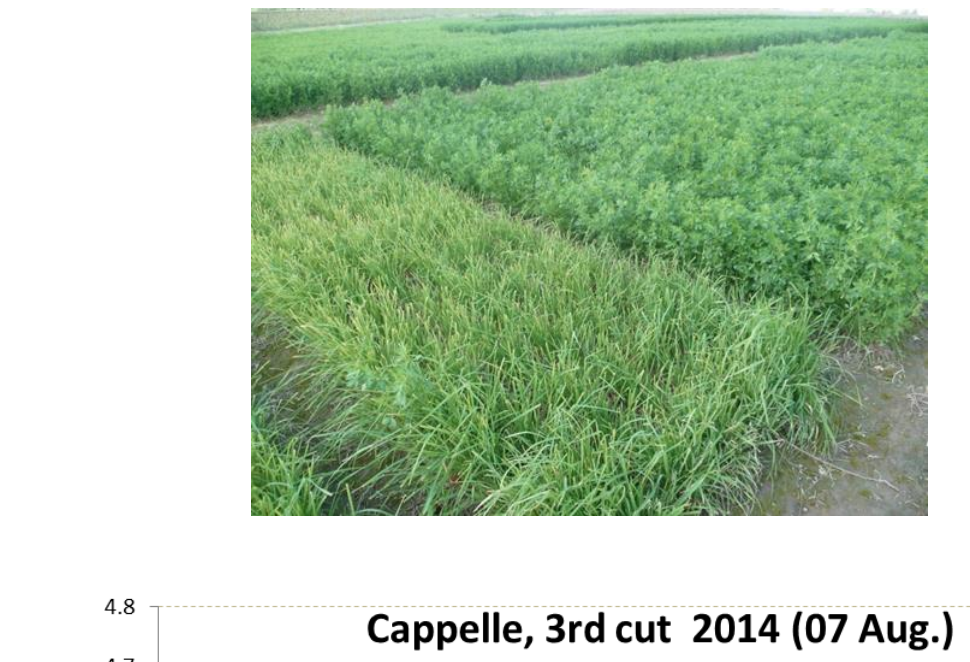

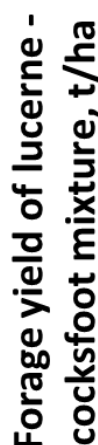

Cappelle, 3rd cut 2014 (07 Aug.)

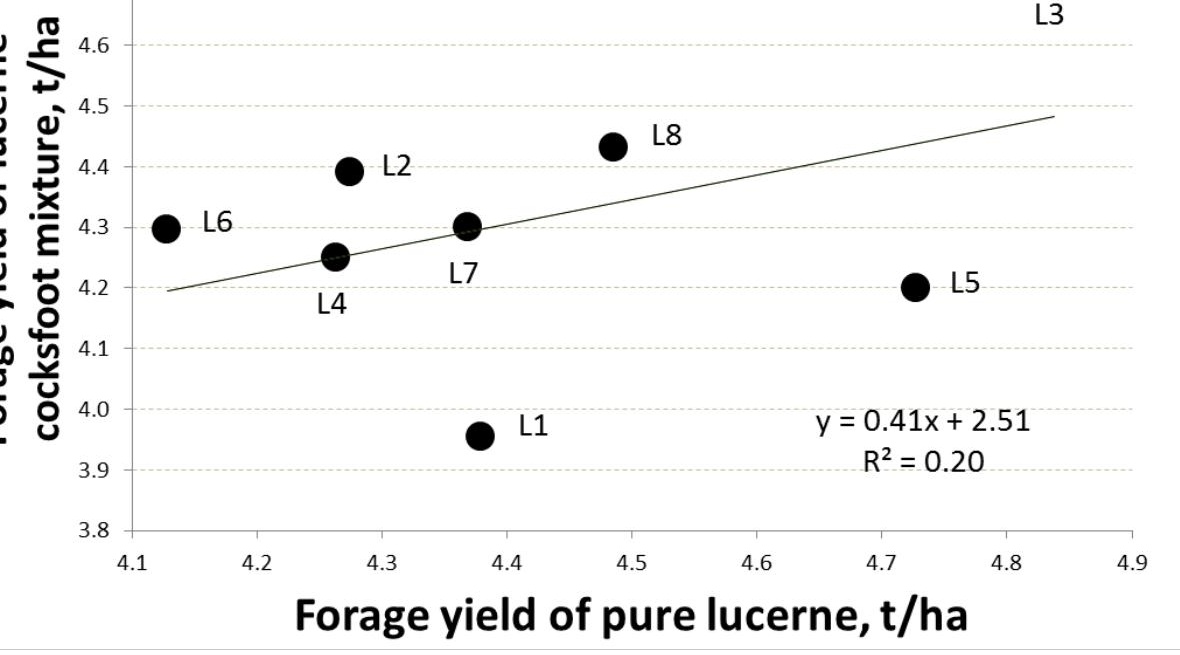

$\rightarrow$ Not exactly ! 
In mixtures, does the ranking of the varieties of one species depend on the variety of the companion species?

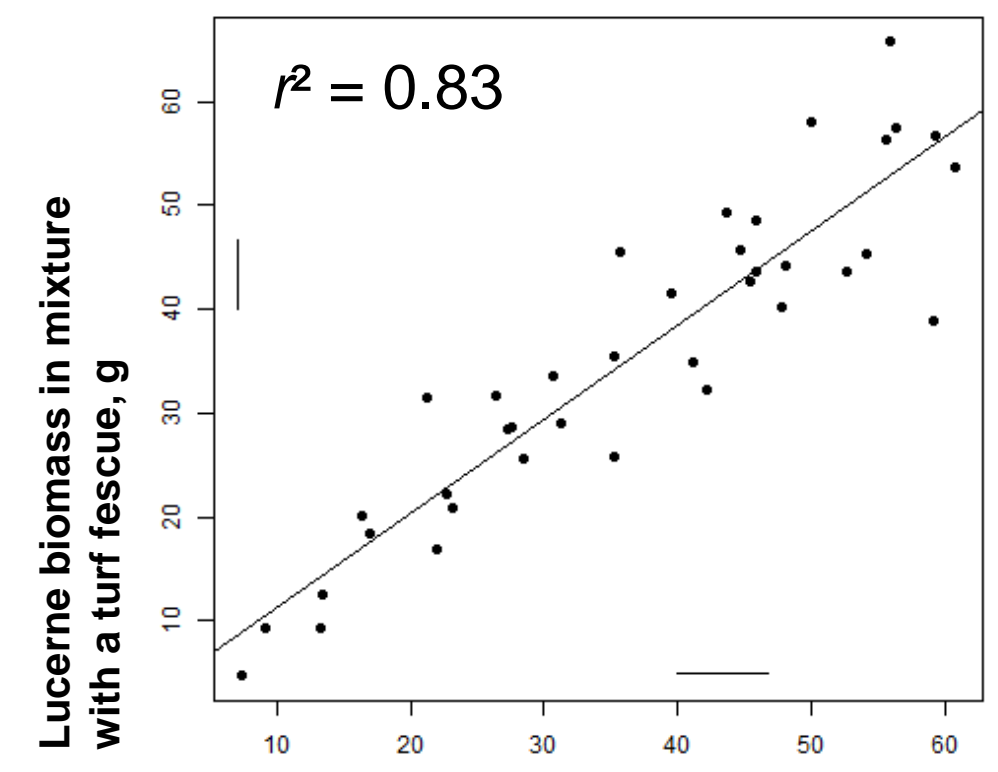

Lucerne biomass in mixture with a forage fescue, $\mathrm{g}$
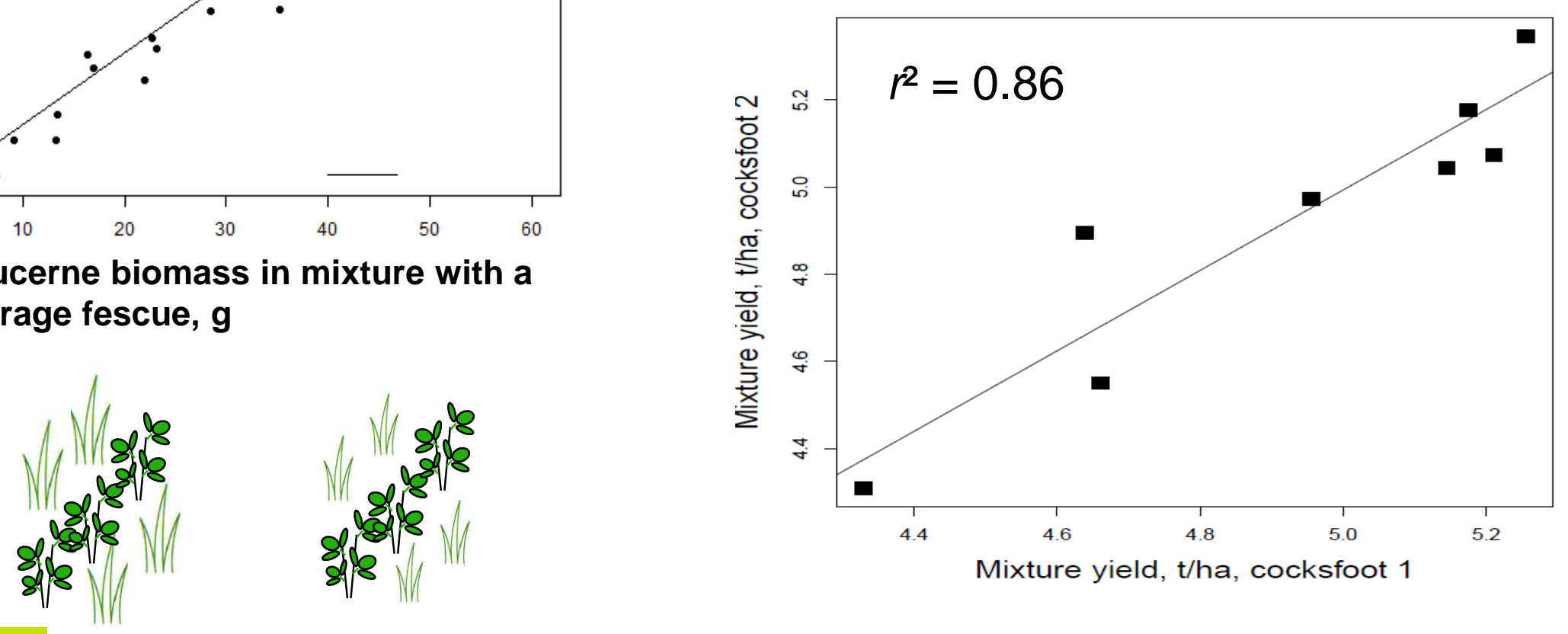

$\rightarrow$ No ! No interaction between lucerne variety and grass variety 


\section{Conclusion}

- it is important to take into account the performance of the varieties in mixtures

during breeding and registration

- the companion variety does not affect the test of target varieties
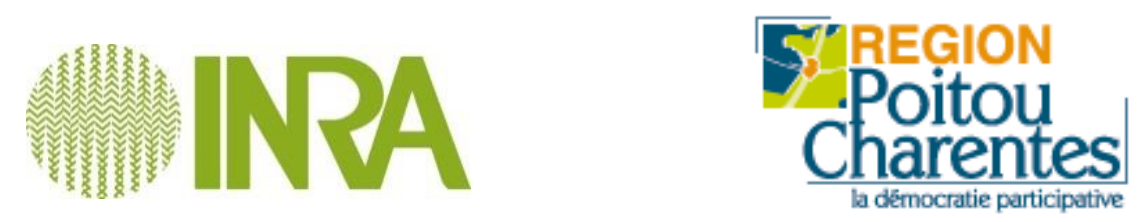

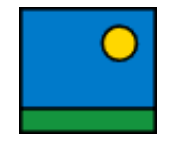

BARENBRUG

Ts.2n
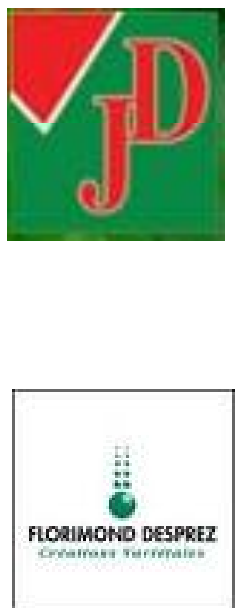